\title{
Netizens' Political Engagement in MaLAYSIA: ImpaCt Of ANTI FaKe NeWS ACT 2018
}

\author{
Rabiah Adawiah Abu Seman \\ UCSI University \\ rabiah@ucsiuniversity.edu.my \\ Nooraneda Mutalip Laidey \\ Asia Pacific University \\ aneda@apu.edu.my \\ Rizwanah Shouket Ali \\ UCSI University \\ rizwanah@ucsiuniversity.edu.my
}

\begin{abstract}
The $14^{\text {th }}$ Malaysia General Elections (GE14) in 2018 witnessed a historic victory for the opposition party led by Tun Mahathir Mohamed against the 60 years government holding party; Barisan National (BN) coalition. Concurrently, it also witnessed social media tools; WhatsApp and Facebook as the most dominant and effective messaging tools, but also a source of fake and unverified news; followed by blogs and other sources. Before the election, the Anti-Fake News Act 2018 had been enforced in April 2018 where any creation, offering, publishing, distribution, or dissemination of fake news is a crime. This research explores the effect of the Anti-Fake News Act 2018 on netizens' political engagement through Facebook and Whatsapp during the 14th Malaysia General Election 2018 with impulsivity and habitual conduct as moderators. Data has been collected from 556 participants through an online survey based on a framework integrating Theory of Planned Behaviour (TPB) and Self Control Theory (SCT). Limited studies have tested the integration of TPB and SCT on knowledge about the Anti-Fake News Act 2018 and political engagement. The findings of the study explain the influence of knowledge, impulsivity, and habitual conduct on political engagement among Malaysian netizens through Facebook and Whatsapp during the GE14. Online political engagement intensity has dropped consequently after the Anti-Fake News Act 2018's enforcement. The relationship between knowledge and political engagement is magnified by netizen's impulsivity. This study further adds to the literature in the area of online political participation and cyber law; uncovering the role of impulsivity and habitual conduct on netizens' political engagement, suggesting the basis for future research in this phenomenon.
\end{abstract}

Keywords: Fake news, online political engagement; Anti-Fake News Act 2018; Theory of Planned Behaviour; Self Control Theory. 


\section{INTRODUCTION}

Information today is abundant and can be received and shared easily and effortlessly. Often, users do not verify the information received before passing it on and habitually and impulsively tend to not use their judgment to certify the validity of the information. This results in the spreading of false information as the truth. To add on, robust technology tools today allow images and content to be easily altered and immediately shared via the internet, thus resulting in a proliferation of fake news. BBC (2017), defines fake news as "false information deliberately circulated by hoax news sites to misinform, usually for political or commercial purposes" (para. 1). Watson (2018) claims that fake news is often made by opportunists who seek financial gain or want to influence political beliefs. The content is designed to provoke anger and reinforce prejudices and often misleading. Fake news is defined as "fictions deliberately fabricated and presented as non-fiction with intent to mislead recipients into treating fiction as fact or into doubting verifiable fact" (Chadwick, 2017, p. 14).

Fabricated information has always existed. Watson (2018) claims that ages ago, the rivalry between Mark Anthony and Julius Caser's son (Octavian) was fueled due to the propagation of fake news involving Cleopatra and Anthony's intentions. This led to Anthony's suicide. Another good example is the fake letters allegedly written by George Washington, the American founding Father on the revolution. These letters led to tarnishing his image and reputation. Another historical example is the 'great Moon Hoax' of 1835, in which the New York Sun published a series of articles about the discovery of life on the moon, thus misleading the general public. Recently, fake news has exploded since the 2016 election of Donald Trump where Trump often uses the term fake to address stories and news sites critical of him (Idid, 2019).

The advent of the internet and social networks has caused fake news to spread exponentially. Social media is now used to influence and manipulate public opinion and political behavior around the world. According to the Malaysia Country Commercial Guide (2018), Malaysia has approximately 25.08 million active internet users (79 percent of the population). The guide reports that of the 31.2 million Malaysians, 24 million are social media users, 21.6 million are unique mobile users and 22 million use social media on their mobile devices. Thus, making Malaysians vulnerable to false information on a social media platform. According to Allcott and Matthew (2017), this finding can be attributed to three main characteristics of social media: (1) social media is affordable in the sense that the fixed market of entering and producing content is small; (2) format of the social media makes it difficult to judge and assess the source; (3) social media users are segregated and people are prone to be connected with the ideological positions.

Alemanno (2018) speaks of approaches to control fake news. He speaks of state intervention where the public authorities control the media to debunk fake news. Thus 'Ministries of truth' are created like the Global engagement center in the US that controls state-sponsored information. Another approach is to make social platforms liable for thirdparty content, where penalties are imposed on entities found of being engaged in fake news. The third approach to controlling media focuses on swamping fake news with truth and this has been practiced by social media like Facebook today where related articles and additional information are posted with controversial topics thus to avoid misleading readers. In line with controlling fake news, Malaysia introduced its law called the Anti-Fake News Act 2018 (Act 803) right before the $14^{\text {th }}$ Malaysian General Election (GE14) to control the effect of social media on the election result. 
Following the BN Coalition's narrow win in the Malaysian 2014 election, Obama's big win during 2008 and 2012's presidential election, Arab Spring in 2011 and Brexit in 2017 (Conway, Kenski \& Wang, 2015; Hanson et al., 2010); the Malaysian government's controlling political party found a need to control information. The period was marked by the popularity of social media such as Facebook, Twitter, and WhatsApp as a source of information (Enli, 2017) for Malaysians. According to the Malaysian Communications and Multimedia Commission (2017), 96.3\% of Malaysians were users of over-the-top (OTT) messaging (such as Whatsapp, Line) and $89.3 \%$ of social networking sites (such as Facebook, Twitter). It was believed that social media can be exploited as a mobilization tool to shape public opinions and as proven in many countries' elections, it served as a platform to disseminate false information (Gorodnichenko et al., 2018). These issues triggered the Malaysian policymakers to consider the power of false dissemination of information and to identify ways to curb activities that can damage an individual, organization, or the country as a whole. Subsequently, the Malaysian government decided to implement the Anti-Fake News Act 2018 (Act 803) before GE14 to control netizens' online behavior. It was expected that the knowledge of the presence of this Act will control the dissemination of false information or fake news.

The objective of the current study is to examine the effects of the presence of the Anti-Fake News Act 2018 (Act 803) on the political engagement behavior of netizens using impulsivity and habitual conduct as a moderator. In essence, the purpose of this research can be divided into four parts. The first being to determine the level of the netzine's knowledge of Act 803. Secondly, to investigate the effect of the knowledge of Act 803 on netizens' political engagement. Thirdly, to analyse the moderating effect of impulsivity on the relationship between awareness of the Anti-Fake News Act 2018 (Act 803) and political information dissemination and lastly, to analyse the moderating effect of habitual conduct on the relationship between awareness of the Anti-Fake News Act 2018 (Act 803) and political information dissemination.

The present study sheds light on this relationship by examining Facebook and Whatsapp users' knowledge, impulsivity, and habitual conduct during the GE14 elections. This study integrates two theories in examining netizens' political engagement: Theory of Planned Behaviour (TPB) and Self Control Theory (SCT). Researchers have explored the effects of SCT in other areas of study (Burt et al., 2006; Jenkins, 2017; Valasik, 2014). However, most studies have not tested the effects of the integration of SCT and TPB on netizens' political engagement. This study believes that in this context, Malaysia is a unique case due to the implementation of the controversial Anti-Fake News Act 2018 that may have an impending effect on online civic engagement in politics. It is understood that the then government's intention of passing the law was to control online political information dissemination. This argument can be supplemented by the fact that the Anti-Fake News Act 2018 (Act 803) was implemented on the 11 April, which was one month before the date of the Malaysian General Elections, 9 May 2018. The current study further attempts to provide evidence of an association between self-control and political information dissemination, which supports the idea that the higher self-control is, the more cautious netizens will be in disseminating political information. It also confirms that the more aware a netizen is of the Act, the higher the possibility that they are not going to disseminate information. 


\section{LITERATURE REVIEW}

\section{Malaysian Anti-Fake News Act 2018 (Act803)}

The Malaysian Anti-Fake News Act 2018 (Act 803) was gazetted by the Malaysian government on the 11th of April 2018 despite being criticised for impeding free speech. It can be understood that the then government's intention of passing the law was to curb the dissenting views on the government. Fake news is loosely translated in Section 2 of Anti-Fake News Act 2018 (Act 803) as "any news, information, data, and reports, which is or are wholly or partly false, whether in the form of features, visuals or audio recordings or in any other form capable of suggesting words or ideas" (p. 5) and this fake news can be disseminated using any form or medium of communication like stories, video content, audio content, and social media content.

Malaysia has several laws in place to limit freedom of the media and freedom of speech. For instance, the Printing Press and Publications Act 1984 makes it an offense for any print media to have any prohibited publications and this offense is punishable with fine and/or imprisonment. Laws on online media include Section 233(1) (a) of the Communications and Multimedia Act 1998 that makes it an offense to use network services to send communication that is false with the intent to annoy, abuse, threaten or harass another person. If found guilty, a person may be fined up to fifty thousand ringgit or imprisoned for up to one year. This act applies to both online media as well as individual users who spread false information using social media. Another law called the defamation law is widely used by public figures like politicians in the event of libel or slander. In Malaysia, defamation can be both a civil and criminal offense. For civil cases, the relevant legislation is the Defamation Act 1957 and for criminal cases, the relevant legislation is covered by Chapter XXI (Sections 499 to 502) of the Malaysian Penal Code.

\section{Online Political Engagement}

Today's digital era is marked by the dissemination of political information mainly through social media channels thus aiming at mobilizing political opinion. The political election and referendum results of many countries (Hanson et al., 2010), discover active online civic engagement (De Zúñiga et al., 2014; Loader, et al., 2014) before polling days due to increasing internal political efficacy among netizens especially young people (Moeller et al., 2013). Social media has always been actively engaged to influence public opinion to switch from apathetic to attentive mobilizer thus resulting in a higher statistic of voters (Xenos, Vromen \& Loader, 2014).

\section{Conceptual Framework: Integrating Theory of Planned Behaviour (TPB) and Self-control Theory (SCT)}

This study proposed a conceptual framework identifying Habitual Conduct and Impulsivity as the moderators of the relationship between Knowledge of Fake-News Act 2018 and Online Political Engagement as shown in Figure 1 and Figure 2.

According to Ajzen and Madden (1986), the Theory of Planned Behaviour (TPB) is an extension of the Theory of Reasoned Action (TRA) (Ajzen, 1991) that describes and predicts humans' behavior based on their intention. An individual's strength of intention influences their behavior performance which is controlled by their motivation to engage in a behavior. An Individual's intention then is controlled by three determinants; attitude towards behavior, subjective norms, and perceived behavior control. What differs TPB from TRA is that the perceived behavior control influence is both intentional and behavioral. 


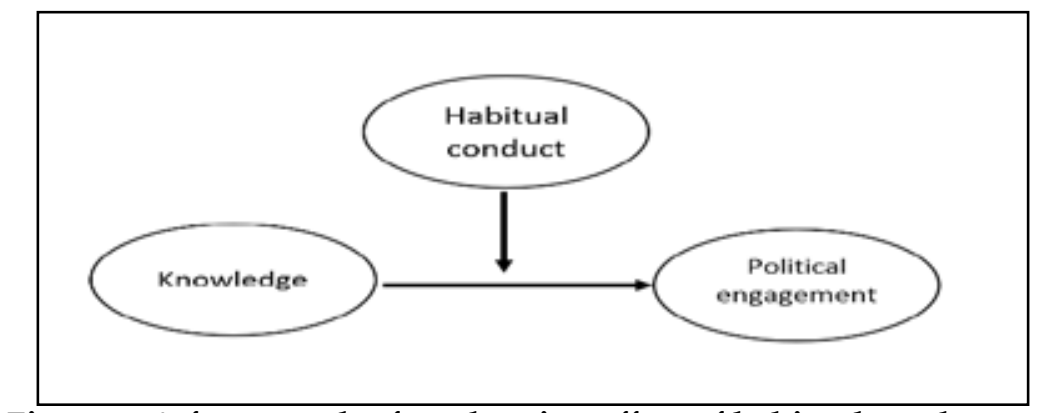

Figure 1: A framework of moderating effect of habitual conduct on political
engagement

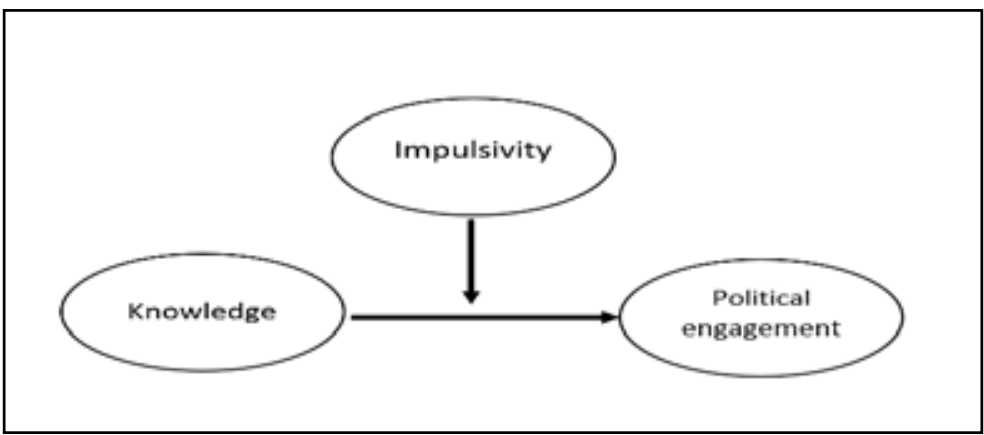

Figure 2: A framework of moderating effect of impulsivity on political engagement

The Self-control theory has received extensive empirical attention especially in the field of crime and parenting. However, most studies have not tested the effects of self-control on the dissemination of political information. The self-control theory suggests that a low level of self-control often correlates with crime and impulsive behaviour conduct (Gottfredson \& Hirschi, 1990). Individuals with a low level of self-control do not consider the long-term consequences of their behaviour, and those with higher self-control consider the long-term consequences of their behaviour (Gottfredson \& Hirschi, 1990). Research by Tittle et. al (2003) supports the hypotheses developed in self-control theory and finds that misbehavior is often correlated with lower self-control (Tittle et. al., 2003). Some researchers associate self-control theory with social control theory by assuming that social control is a major determinantal factor of self-control (Hirschi, 2004). It is also argued that self-control is also dictated by many other factors and related concepts of choice, willpower, self-regulation, human agency, and personal autonomy. Research has shown that self-control plays an important role in religious and spiritual traditions where concepts of self-restraint, internal self-regulation, and management of external behavior (e.g., right speech, right action) are integral to control (Shapiro et al., 2010). Individuals with high impulsivity tend to have low self-control.

Habitual conduct behavior is defined as automatic behavior "performed efficiently, unintentionally, without awareness and conscious control such as smoking, shopping or snacking. It may also be described as "addictive behavior" (Baumeister, 2018). Wood, et.al (1997) researched groups of criminals and non-criminals and found that habitual criminality is intrinsically rewarding and is sustained partly through positive physiological and psychological sensations. 
The hypothesis are as follows:

- H 1: Habitual conduct significantly moderates the relationship between Knowledge and Online Political Engagement.

- H 2: Impulsivity significantly moderates the relationship between Knowledge and Online Political Engagement.

\section{METHODOLOGY}

The current study is focused on investigating the relationship between fake news law and political engagement. Sampling is confined to any Malaysian over the age of 21 years old who is eligible to vote in the Malaysian General Election of 2018. Additionally, the respondent has been a user of either Facebook and/or Whatsapp and has a general understanding of the procedures of the Malaysian general elections. Data were collected using a self-administered survey, distributed to a sample of internet users at a large through Facebook and Whatsapp. Data were collected over two weeks with a total of 566 respondents.

\section{Instrument}

Knowledge, Impulsivity, Habitual Conduct, and Online Political Engagement were measured using a five-point Likert scale, $1=$ "strongly disagree" to $5=$ "strongly agree". Netizens' political engagement was measured through civic engagement activities limited to information sharing behaviour proxy where respondents were asked about the amount of time they spent on social media and the frequency in reading and sharing political-related information on Whatsapp and Facebook. All constructs in the framework of online political engagement were tested using a reliability test that resulted in Cronbach's alpha more than 0.6 indicating the reliability of the questionnaire used for data collection.

\section{Participants}

Most participants are in the 21 to 30 years old age group (48.9\%), followed by the 31 to 40 years old group $(32.4 \%)$. The majority of them are full-time students $(45.3 \%)$ and executives or associates (29.5\%), with more than half, had a bachelor's degree education (54.0\%). Participants usually spent one to three hours daily on Facebook (64.0\%) and Whatsapp (43.2\%). A small percentage of the participants spent 10 hours daily on Facebook $(2.2 \%)$ and Whatsapp (13.7\%). Additionally, the mean for reading news on GE14 through Facebook is 3.504 and Whatsapp is 2.993.

\section{FINDINGS}

On looking at the level of knowledge on the Anti-Fake News Act 2018 (Act 803) amongst Malaysian social media users, it was found that about $21.6 \%$ of the participants have an average knowledge of the act (see Table 1). The majority of the users claimed to know of the Act $(76.3 \%)$. 
Table 1: Distribution level of participants' knowledge of Act 803 ( $n=556)$

\begin{tabular}{ccc} 
Knowledge level & $N$ & Percentage (\%) \\
Low & 12 & 2.2 \\
Average & 120 & 21.6 \\
High & 424 & 76.3 \\
\hline
\end{tabular}

Table 2 explains Model 1, indicating that on the whole, the model with only Knowledge predictor is insignificant to predict Political Engagement $(F=1.140, p>0.05)$ with a variance of only $2 \%\left(R^{2}=0.2\right)$. Based on Model 2 , the model with predictor Knowledge and moderating variables (Impulsivity and Habitual Conduct) is significant $(F=142.807, p<0.05)$, thus predicting the Political Engagement score to indicate a linear relationship between the variables in the model and the potential of Impulsivity and Habitual Conduct as moderators in the model. With the interaction terms included, there is an additional $43.5 \%$ change $\left(R^{2}\right.$ change $=0.435$ ) of the variance in Political Engagement making it $43.7 \%$.

According to Table 2, the regression analysis result indicates a significant association between Knowledge and Political Engagement $(\beta=-0.165, S E=0.032$, Beta $=-0.182, p=0.000)$. The coefficient for Knowledge is negative $(B=-0.165)$, thus indicating that the increase in score of Knowledge by a unit, will result in a drop of Political Engagement by 0.165 points. This is explained further through a Paired T-Test of Political Engagement before and after the implementation of Act 803 as participants acquire the Knowledge of Act 803 . There is a significant different of Political Engagement $(p<0.05)$ with $T$ value $9.814(p=0.000)$. Mean of Political Engagement before Act 803 is recorded at 15.7194 and dropped to 14.5971 after Act 803.

Table 2 : Summary of Regression of predictor of Political Engagement with moderating variables Impulsivity and Habitual Conduct $(n=556)$

\begin{tabular}{|c|c|c|c|}
\hline & $\beta$ & $S E \beta$ & Beta \\
\hline \multicolumn{4}{|l|}{ Model 1} \\
\hline Intercept & 12.693 & 1.802 & \\
\hline Knowledge & 0.041 & 0.38 & 0.045 \\
\hline $\mathrm{R}^{2}$ & 40.9 & & \\
\hline $\mathrm{F}$ & 1.140 & & \\
\hline Total $R^{2} \%$ & 43.7 & & \\
\hline \multicolumn{4}{|l|}{ Model 2} \\
\hline Intercept & 12.253 & & \\
\hline Knowledge & $-0.165^{*}$ & 0.032 & -0.182 \\
\hline Knowledge X Impulsivity & $0.234^{*}$ & 0.001 & 0.692 \\
\hline Knowledge X Habitual Conduct & 0.000 & 0.001 & 0.012 \\
\hline Incremental $R^{2} \%$ & 43.5 & & \\
\hline $\mathrm{F}$ & $127.469^{*}$ & & \\
\hline Total $R^{2} \%$ & 43.7 & & \\
\hline
\end{tabular}

Note. ${ }^{*} p<0.001$ 
From Table 2, it is summarized that the interaction between Knowledge and Impulsivity contributes the most to Political Engagement at $69.2 \%$ (Beta $=0.692$ ), followed by Knowledge alone at $18.2 \%($ Beta $=-0.182)$.

Based on Table 3, the interaction between Knowledge and Habitual Conduct is insignificant at $\beta=0.000$ ( $S E=0.001, p=0.749$ ). Therefore, hypothesis 2 is rejected. However, the interaction between Knowledge and Impulsivity is significant at $\beta=0.023$ (SE $=0.001, p=$ 0.000); indicating an increase of Political Engagement by 0.023 points at any 1 -point increase of Impulsivity. Therefore hypothesis 1 is accepted.

\section{Table 3: Regression of Knowledge and Political Engagement with moderating variables Self-control and Habitual Conduct $(n=556)$}

\begin{tabular}{lccccc} 
& SS & Df & MS & F & Sig. \\
Regression & 8892.380 & 3 & 2964.127 & 142.807 & ${ }^{*} 0.000$ \\
Residual & 11457.375 & 552 & 20.756 & & \\
& B & S. Error & Beta & T & Sig. \\
Intercept & 12.253 & 1.386 & & 8.839 & ${ }^{*} 0.000$ \\
Knowledge & -0.165 & 0.032 & -0.182 & -5.105 & ${ }^{*} 0.000$ \\
Knowledge X Impulsivity & 0.023 & 0.001 & 0.692 & 19.175 & ${ }^{*} 0.000$ \\
Knowledge X Habitual & 0.000 & 0.001 & 0.012 & 0.320 & 0.749 \\
Conduct & & & & & \\
\hline
\end{tabular}

Note. $R=0.661 ; R^{2}$ change $=0.435 ; R^{2}=0.437 ;$ Adj. $R^{2}=0.434$

*significant at $p<0.001$

\section{DISCUSSION}

The result found that hypothesis 1 is rejected, where habitual conduct did not significantly moderate the relationship between knowledge and political engagement. This result contradicts the past empirical conducted on criminals that found a sustained behaviour due to habitual criminality (Wood, et.al, 1997). Criminal behaviour continues because habitual criminality gives the criminal an intrinsic reward that is positive physiological and psychological sensations. However, the habitual criminality did not affect the non-criminal group in the study.

The second hypothesis was accepted; where impulsivity was identified to moderate the relationship between knowledge and political engagement. Similar to the past studies (Gottfredson \& Hirschi, 1990; Shapiro, 2010; Tittle et. al., 2003), impulsivity or low self-control plays a role in human behaviour. This study has found a big change in a political engagement with the inclusion of impulsivity in the equation. Despite the new act introduced, individuals with high impulsivity continue engaging in a political posts on social media. This shows that impulsivity or self-control is not controlled by social control that is regulations in the society as claimed by other literature (Hirschi, 2004 in Baumeister \& Vohs, 2004).

Theoretically, Social Control Theory is applicable to be integrated with TPB in the study of political engagement through social media. Despite being used in criminal studies, it also 
suitable to be applied and regarded as a moderator to political engagement behaviour for Malaysian context.

Practically, the finding of this study gives a clear understanding of the impact of the introduction of the Fake News Act 803. The Barisan Nasional Government introduced the Fake News Act 803 to curb and control online political engagement activities amongst netizens. Accordingly, the study found that the imposing of the new act resulted in a drop in information sharing activities among Malaysian netizens before the Malaysia 14th General Elections. However, impulsivity is not a behavior that can be possibly disregarded in the effort of behavior control, being a long-learned behavior in any individual's life. It possesses a big influence on netizen's political engagement activities. Yet, the effort by the then government ruling party to control netizens' political engagement through Act 803 has successfully reduced the political information sharing during the GE14. Individuals with high impulsivity tend to have low self-control over regulations despite their acknowledgment of the fine for any proprietor of Act 803. They continue to engage more in online political activities; sharing of political news information due to their critical attitude towards the then government ruling party's policies that creates oppressed feeling (Hope \& Jagers, 2014).

\section{CONCLUSION}

Enforcement and awareness of cyberlaw such as the Anti-Fake News Act 2018 are effective in controlling online political engagement through online platforms. Similar to Barrack Obama's election win in 2012, the previous election; Malaysia GE13 is also known as social media election. The snowball effect of information explosion through information sharing on social media is unpredictable and risky especially on the account of a country's direction. This signifies a need for controlling online information dissemination from the spreading of fake information.

\section{REFERENCES}

Ajzen, I. (1991). The theory of planned behaviour. Organizational Behaviour and Human Decision Process, 50, 179-211.

Ajzen, I., \& Madden, T. J. (1986). Prediction of goal-directed behaviour: Attitudes, intentions and perceived behaviour control. Journal of Experimental Social Psychology, 22, 453-474. https://doi.org/10.1016/0022-1031(86)90045-4

Alemanno, A. (2018). How to counter fake news? A taxonomy of anti-fake news approaches. European Journal of Risk Regulation, 9, 1-5. https://doi.org/10.1017/err.2018.12

Allcott, H., \& Matthew, G. (2017). Social media and fake news in the 2016 election. The Journal of Economic Perspectives, 31(2), 211-236. https://doi.org/10.1257/jep.31.2.211

Baumeister, R. F. (2018). Self-regulation and self-control. Taylor \& Francis.

BBC. (2017, March). Written evidence submitted by the BBC (FNW0114). http://data.parliament. uk/writtenevidence/committeeevidence.svc/evidencedocument/culture-media-andsport-committee/fake-news/written/48758.html

Burt, C. H., Simons, R. L., \& Simons, L. G. (2006). A longitudinal test of the effects of parenting and the stability of self-control: Negative evidence for the general theory of crime. Criminology, 44(2), 353-396. 
Chadwick, P. (2017, May 12). Defining fake news will help us expose it. The Guardian. https:// www.theguardian.com/media/commentisfree/2017/may/12/defining-fake-news-willhelp-us-expose-it, para.14.

Conway, B. A., Kenski, K., \& Wang, D. (2015). The rise of Twitter in the political campaign: searching for intermedia agenda-setting effects in the Presidential Primary. Journal of Computer-Mediated Communication, 20(4), 363-380. https://doi.org /10.1111/jcc4.12124

De Zúñiga, H. G., Copeland, L., \& Bimber, B. (2014). Political consumerism: Civic engagement and the social media connection. New Media \& Society, 16(3), 488-506. https://doi. org/10.1177/1461444813487960

Enli, G. (2017). Twitter as arena for the authentic outsider: Exploring the social media campaigns of trumps and clinton in the 2016 US presidential election. European Journal of Communication, 32(1), 50-61. https://doi.org/10.1177/0267323116682802

Jenkins, W. J. (2017). An Analysis of Michael R. Gottfredson and Travish Hirschi's. Lodon: Macat Library

Gorodnichenko, Y., Pham, T., \& Talavera, O. (2018). Social media, sentiment and public opinions: Evidence from \#Brexit and \#USElection. National Bureau of Economic Research. https://doi.org/10.3386/w24631

Gottfredson, M. R., \& Hirschi, T. (1990). A general theory of crime. Stanford University Press.

Hanson, G., Haridakils, P. M., Cunninghal, A. W., Sharma, R., \& Ponder, J. D. (2010). The 2008 presidential campaign: Political cynicism in the age of Facebook, Myspace and YouTube. Mass Communication E Society, 13 (5): 584-607. https://doi.org/10.1080/152054 36.2010.513470

Hirschi, T. (2004). Self-control and crime. In R. F. Baumeister \& K. D. Vohs (Eds.), Handbook of self-regulation: Research, theory, and applications (pp. 537-552). New York: Guilford Press.

Hope, E. \& Jagers, R. (2014). The role of sociopolitical attitudes and civic education in the civic engagement of black youth. Journal of Research on Adolescents, 24, 460-470. https:// doi.org/10.1111/jora.12117

Idid. (2019, May 3). More than fake news. Opinion manipulation. Forum Fake News and Politics in Malaysia. Centre for Media and Information Warfare (CMIWS), Faculty of Communication and Media Studies, Universiti Teknologi MARA, Malaysia.

Loader, B. D., Vromen, A., \& Xenos, M. (2014). The networked young citizen: Social media, political participation and civic management. Information, Communication E Society, 17(2), 143-150. https://doi.org/10.1080/1369118X.2013.871571

Malaysian Communications and Multimedia Commission. (2017). Internet users survey 2017: Statistical brief number twenty-one. Malaysian Communications and Multimedia Commission. Retrieved May 23, 2018, from https://www.mcmc.gov.my/skmmgovmy/ files/17/17b084f3-cdc1-4b42-ab15-2b92aa6c0170/files/assets/basic-html/page-1.html

Malaysia Country Commercial Guide. (2018, July 19). Retrieved from https://www.export. gov/article?id=Malaysia-E-Commerce

Moeller, J., de Vreese, C., Esser, F., \& Kunz, R. (2013). Pathway to political participation: The influence of online and offline news media on internal efficacy and turnout of first-time voters. American Behavioural Scientist, 58(5), 689-700. https://doi. org/10.1177/0002764213515220 
Shapiro, D. H., Shapiro, S. L., Astin, J. A., \& Shapiro, J. (2010). Self-control. In I. B. Weiner \& W. E. Craighead (Eds.), The corsini encyclopedia of psychology, (pp. 1-2). New York: John Wiley \& Sons. https://doi.org/10.1002/9780470479216.corpsy0833

Tittle, C. R., Ward, D. A., \& Grasmick, H. G. (2003). Gender, age, and crime/deviance: A challenge to self-control theory. Journal of Research in Crime and Delinquency, 40(4), 426453. https://doi.org/10.1177/0022427803256074

The Guardian. (2017, March). Written evidence submitted by Guardian News \& Media (FNW0096). https://data.parliament.uk/writtenevidence/committeeevidence.svc/evidencedocument/ cul ture-media-and-sport-committee/fake-news/written/48259.html

Valasik, M. (2014). Self-control theory. In J. S. Albanese (Eds.), The encyclopedia of criminology and criminal justice, (pp. 1-5). New York: John Wiley \& Sons. https://doi. org/10.1002/9781118517383.wbeccj040.

Watson, C. A. (2018). Information literacy in a fake/false news world: An overview of the characteristics of fake news and its historical development. International Journal of Legal Information, 46(2), 93-96. https://doi.org/10.1017/jli.2018.25

Wood, P. B., Gove, W. R., Wilson, J. A., \& Cochran, J. K. (1997). Nonsocial reinforcement and habitual criminal conduct: An extension of learning theory. Criminology, 35(2), 335-366. https://doi.org/10.1111/j.1745-9125.1997.tb00879.x

Xenos, M., Vromen, A., \& Loader, B. (2014). The great Equalizer? Patterns of social media use and youth political engagement. Information, Communication $\mathcal{E}$ Society, 17(2), 151-167. https://doi.org/10.1080/1369118X.2013.871318 